Article

\title{
Coriolus Versicolor Downregulates TLR4/NF- Cascade in Dinitrobenzenesulfonic Acid-Treated Mice: A Possible Mechanism for the Anti-Colitis Effect
}

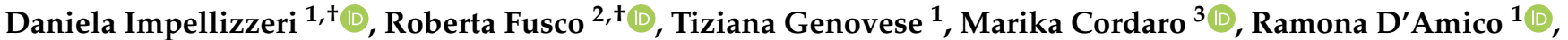 \\ Angela Trovato Salinaro ${ }^{4}\left(\mathbb{D}\right.$, Maria Laura Ontario ${ }^{4}$, Sergio Modafferi ${ }^{4}$, Salvatore Cuzzocrea ${ }^{1,5}, *$ (D), \\ Rosanna Di Paola ${ }^{6, *(D)}$, Vittorio Calabrese ${ }^{4, \ddagger}$ (D) and Rosalba Siracusa $1, \neq(\mathbb{D}$
}

check for

updates

Citation: Impellizzeri, D.; Fusco, R.; Genovese, T.; Cordaro, M.; D'Amico, R.; Trovato Salinaro, A.; Ontario, M.L.; Modafferi, S.; Cuzzocrea, S.; Di Paola, R.; et al. Coriolus Versicolor Downregulates TLR4/NF-KB

Signaling Cascade in

Dinitrobenzenesulfonic Acid-Treated Mice: A Possible Mechanism for the Anti-Colitis Effect. Antioxidants 2022, 11, 406. https://doi.org/10.3390/ antiox11020406

Academic Editors:

Stefania Pizzimenti, Giuliana Muzio and Giuseppina Barrera

Received: 17 January 2022

Accepted: 15 February 2022

Published: 17 February 2022

Publisher's Note: MDPI stays neutral with regard to jurisdictional claims in published maps and institutional affiliations.

Copyright: (c) 2022 by the authors. Licensee MDPI, Basel, Switzerland. This article is an open access article distributed under the terms and conditions of the Creative Commons Attribution (CC BY) license (https:// creativecommons.org/licenses/by/ $4.0 /)$.
1 Department of Chemical, Biological, Pharmaceutical and Environmental Sciences, University of Messina, 98166 Messina, Italy; dimpellizzeri@unime.it (D.I.); tiziana.genovese@unime.it (T.G.); rdamico@unime.it (R.D.); rsiracusa@unime.it (R.S.)

2 Department of Clinical and Experimental Medicine, University of Messina, 98125 Messina, Italy; rfusco@unime.it

3 Department of Biomedical, Dental and Morphological and Functional Imaging, University of Messina, 98125 Messina, Italy; marika.cordaro@unime.it

4 Department of Biomedical and Biotechnological Sciences, University of Catania, 95125 Catania, Italy; trovato@unict.it (A.T.S.); marialaura.ontario@ontariosrl.it (M.L.O.); sergio.modafferi@studium.unict.it (S.M.); calabres@unict.it (V.C.)

5 Department of Pharmacological and Physiological Science, Saint Louis University School of Medicine, Saint Louis, MO 63104, USA

6 Department of Veterinary Science, University of Messina, 98168 Messina, Italy

* Correspondence: salvator@unime.it (S.C.); dipaolar@unime.it (R.D.P.); Tel.: +39-090-676-5208 (S.C. \& R.D.P.)

+ These authors contributed equally to this work.

$\ddagger$ Rosalba Siracusa and Vittorio Calabrese share senior authorship.

Abstract: Inflammatory bowel diseases (IBDs) are disorders characterized by chronic inflammation of the intestinal tract. The focus of the present study was to examine the effect of the fungus Coriolus versicolor $(C V)$, underlining its correlation with Toll-like receptors 4 (TLR4) and nuclear factor erythroid 2-related factor 2 (Nrf2); we aim to evaluate its anti-inflammatory and antioxidant effect in mice exposed to experimental colitis. The model was induced in mice by colon instillation of dinitrobenzenesulfonic acid (DNBS), CV was administered orally (200 $\mathrm{mg}$ per $\mathrm{kg}$ ) daily for 4 days. On day 4 , the animals were killed, and the tissues collected for histological, biochemical, and molecular analyses. Four days after DNBS administration, CC motif chemokine ligand 2 (CCL2), prostaglandin E2 (PGE2), interleukin-1 $\beta$ (IL-1 $\beta$ ), and tumor necrosis factor- $\alpha$ (TNF- $\alpha$ ) production increased in association with damage to the colon. Neutrophil infiltration, as assessed by myeloperoxidase (MPO) activity, in the mucosa was associated with overexpression of P-selectin and intercellular adhesion molecule 1 (ICAM1). Immunohistochemistry for nitrotyrosine and poly-(ADP-Ribose)-polymerase (PARP) showed evident stain in the inflamed colon. Treatment with $C V$ significantly reduced the appearance of colon changes and weight loss. These effects were associated with a remarkable ability of $C V$ to reduce the expression of TLR4 and modulate the pathway of nuclear factor kappa-light-chainenhancer of activated B cells (NF-kB). This improved the colon architecture, reduced MPO activity, the release of proinflammatory cytokines, the presence of nitrotyrosine, and the hyperactivation of PARP, as well as the up-regulation of P-selectin and ICAM1. Furthermore, we studied the action of $\mathrm{CV}$ on the Nrf2/HO-1 pathway, which is important for maintaining redox balance, demonstrating that $C V$ by significantly increasing both enzymes is able to counteract the oxidative stress induced by DNBS. Taken together, our results clearly show that this natural compound can be considered as a possible dietary supplement against colitis.

Keywords: inflammatory bowel diseases; inflammation; oxidative stress; natural compounds; TLR4 


\section{Introduction}

Inflammatory bowel disease (IBD) is a term used to call ailments involving chronic inflammation of the digestive tract. There are mainly two types of IBD: ulcerative colitis and Crohn's disease. Ulcerative colitis is characterized by inflammation and ulcer formation along the superficial lining of the colon and rectum. Crohn's disease, on the other hand, is characterized by inflammation of the lining of the digestive tract that can often comprise the deeper layers of this tract [1].

People of different ages can get IBD, but it is usually diagnosed between the ages of 15 and 40 [2].

Both types of IBD are generally characterized by diarrhea, rectal bleeding, abdominal pain, fatigue, and weight loss. IBD can therefore be debilitating and sometimes lead to lifethreatening complications. The causes of IBD are still unclear, but it is thought to be caused by a combination of factors, including: genetics, immune system changes, and lifestyle [3].

What has certainly been observed over the years is that both types of IBD are characterized by an increase in pro-inflammatory cytokines, chemokines, and adhesion molecules that increase the damage to the barrier function and perpetuate the inflammatory process $[4,5]$. To confirm this there are studies conducted on mucous biopsies of patients with IBD [6].

Furthermore, recently, various studies are focusing on reactive nitrogen and oxygen species (RNS and ROS) as etiological causes for IBD [7]. The intestine represents the main place of origin of pro-oxidant molecules, due to a surplus of food constituents, microbes and interactions between immune cells [7]. Furthermore, a reduction in antioxidant capacity has been highlighted in patients with IBD and in asymptomatic subjects [8]. To counteract the increase in oxidative stress, intestinal cells require enzymatic and non-enzymatic antioxidant systems [9]. Therefore, oxidative stress concomitant with immune activation and inflammation could contribute to the tissue damage and fibrosis that characterize intestinal diseases [10].

There is currently no cure for ulcerative colitis or Crohn's disease. Most existing treatments aim to relieve symptoms and prevent them from returning and include specific diets, lifestyle changes, medications (sulfasalazine; corticosteroids; immunosuppressive agents; and several biologics, for example anti-TNF- $\alpha$ antibodies) and, in the most serious cases, surgery [11-14].

Since oxidative stress and inflammation contribute to tissue damage during colitis, the administration of natural compounds with antioxidant and anti-inflammatory activity has recently been proposed as a treatment for IBD $[13,15]$. Mushrooms have been used in traditional medicine for many years [16]. Several studies have investigated the medicinal action that mushrooms and their extracts possess, including anti-tumor, immunomodulatory, anti-oxidant, anti-inflammatory, antiviral, antibacterial, and hepatoprotective effects [17].

Mushrooms have been shown to stimulate the host's immune system. This appears to be due to the high content of $\beta$-glucans, which activate different types of immune cells and stimulate the cytokine response $[17,18]$.

The polysaccharopeptides produced by Coriolus versicolor $(\mathrm{CV})$ are widely used to integrate chemotherapy and radiotherapy of cancer and infectious diseases [19]. Over the years, $\mathrm{CV}$ has been shown to have both anticancer and immunomodulatory properties as well as anti-inflammatory and antioxidant properties. In a mouse model of Alzheimer's disease, $\mathrm{CV}$ has been shown to improve spatial memory by activating antioxidants such as superoxide dismutase (SOD) and catalase (CAT) and inhibiting pro-inflammatory cytokines [20]. In our recent study, $C V^{\prime}$ s ability to reduce inflammatory processes induced by traumatic brain injury (TBI) and inducing neurodegeneration has emerged. From the characterization of $C V$, it emerged that the main components of this fungus are hexadecanoic acid, hexadecane, and vanillic acid which are probably responsible for the anti-inflammatory and anti-oxidant action observed in an experimental model of TBI [21].

Based on the data in the literature, in the present study, we used a model of colitis induced by dinitrobenzenesulphonic acid (DNBS) to evaluate the effects of the fungus $C V$ 
on the regulation of inflammatory processes and oxidative stress and in particular the modulation of Toll-like receptors 4 (TLR4) and nuclear factor erythroid 2-related factor 2/heme oxygenase 1 (Nrf2/HO-1) pathway.

\section{Materials and Methods}

\subsection{Animals}

CD1 male mice (25-30 g) were obtained from Envigo (Milan, Italy) and were housed in a sterile environment with water and food suitable for mice. The cages in which the animals were kept were in rooms with a temperature of $22 \pm 1^{\circ} \mathrm{C}$ and day/night cycles of $12 \mathrm{~h}$ each. They were kept in a controlled location and received food and water ad libitum. The University of Messina Review Board for animal care (OPBA approval number 89126.24/2021) approved the study. All in vivo experiments followed the new directives of the USA, Europe, Italy, and the ARRIVE guidelines.

\subsection{Colitis Induction and Treatment}

The intra-rectal injection of DNBS (4 mg in $100 \mu \mathrm{L}$ of $50 \%$ ethanol per mouse) was executed on day 0 for induction of colitis as previously reported [22].

$\mathrm{CV}$ biomass including mycelium and primordia of the mushroom, offered by Mycology Research Laboratories Ltd. (MRL, Luton, UK), as the product commercially existing, was used for investigation. Ideal quantity $(200 \mathrm{mg} / \mathrm{kg})$ was chosen according to the dose used in clinical trials with cancer or human papilloma virus (HPV) patients (3 g/day) [23], a regimen also confirmed by studies in rat and mice [21,24,25]. After 4 days to colitis induction, mice were sacrificed and the colon was harvested, opened, rinsed, and processed for histology and biochemical analyses.

\subsection{Experimental Design}

All animals were randomized in the indicated groups (10 mice for each group):

1. Sham + vehicle: vehicle solution (saline) was administered daily orally and animals were sacrificed on day 4 after intrarectal administration of vehicle (100 $\mu \mathrm{L}$ of $50 \%$ ethanol);

2. Sham $+C V$ : mice were subjected to the procedures as above and animals were treated orally with $C V$ (data are not shown in all results as no significant differences were observed with the Sham + vehicle);

3. DNBS: vehicle was administered daily orally, and animals were sacrificed on day 4 after administration of DNBS.

4. DNBS + CV: mice were administered intrarectal DNBS as described above and $C V$ (200 $\mathrm{mg} / \mathrm{kg}$ dissolved in saline, orally) was administered every $24 \mathrm{~h}$, starting $1 \mathrm{~h}$ after administration of DNBS and animals were sacrificed on day 4 after colitis induction.

\subsection{Body Weight and Macroscopic Analysis of Colon Damage}

Mice were weighed all day, from day 0 until the day of sacrifice. The colon tissue was collected and untied by a longitudinal incision. Two impartial observers reported the severity of colon damage following standardized criteria as described above [26]. Briefly, macroscopic colon damage was evaluated and scored according to the following criteria: $0=$ no damage; 1 = localized hyperemia without ulcers; $2=$ linear ulcers with no important inflammation; 3 = linear ulcers with inflammation at one site; $4=$ two or more major sites of inflammation and ulceration covering more than $1 \mathrm{~cm}$ along the length of the colon; and 5-8 = one point is added for each $\mathrm{cm}$ of ulceration beyond an initial $2 \mathrm{~cm}$.

\subsection{Histological Evaluation}

Colon were treated with hematoxylin and eosin (H\&E) staining for histological valuation; the semi-quantitative assessment of the damage was evaluated according to a score ranging from 0 to 4 as described in literature [27], in a blinded mode by two qualified pathologists using a Leica DM6 microscope (Leica Microsystems SpA, Milan, Italy) associated with Leica LAS X Navigator software (Leica Microsystems SpA, Milan, Italy). 
Briefly the assigned score corresponded to the following characteristics: $0=$ no damage; $1=$ mild damage with focal epithelial edema and necrosis; 2 = moderate damage with widespread swelling and necrosis of the villi; 3 = severe damage with necrosis and presence of neutrophil infiltrate in the submucosa; 4 = very severe damage with diffuse necrosis and massive infiltrate of neutrophils and hemorrhage.

\subsection{Malondialdehyde (MDA) Assay}

As previously reported, MDA levels, a marker of lipid peroxidation, were determined in colon tissue 4 days after DNBS administration [28,29]. Briefly, the colon was homogenized in a $1.15 \% \mathrm{KCl}$ solution. About $100 \mu \mathrm{L}$ of homogenate was added to a reaction mixture containing $8.1 \%$ sodium dodecyl sulfate, $20 \%$ acetic acid ( $\mathrm{pH} 3.5$ ), $0.8 \%$ thiobarbituric acid, and distilled water. The samples were boiled for $1 \mathrm{~h}$ at $95{ }^{\circ} \mathrm{C}$ and centrifuged at $3000 \times g$ for $10 \mathrm{~min}$. The absorbance was measured by spectrophotometer at $532 \mathrm{~nm}$.

\subsection{Myeloperoxidase (MPO) Activity}

MPO activity, an indicator of neutrophil infiltration, was determined by spectrophotometric assay with tetramethylbenzidine as the substrate. The collected colons were homogenized in a solution containing $0.5 \%$ hexadecyl-trimethyl-ammonium bromide dissolved in potassium phosphate buffer $(10 \mathrm{mM} \mathrm{pH} \mathrm{7)}$ and subsequently centrifuged for $30 \mathrm{~min}$ at $20,000 \times \mathrm{g}$ at $4{ }^{\circ} \mathrm{C}$. Part of the supernatant was then allowed to react with a solution of tetramethylbenzidine $(1.6 \mathrm{mM})$ and $\mathrm{H}_{2} \mathrm{O}_{2}(0.1 \mathrm{mM})$. A reading at $650 \mathrm{~nm}$ was performed using a spectrophotometer. MPO activity was expressed in unit of MPO/g of wet tissue and was measured as the quantity of enzyme degrading $1 \mu \mathrm{M}$ of peroxide per $\min$ at $37^{\circ} \mathrm{C}[29,30]$.

\subsection{Immunohistochemical Evaluation of $\mathrm{CD}^{+}, \mathrm{CD} 8^{+}$, Cell Adhesion Molecules (ICAM-1,} P-Selectin), Poly-(ADP-ribose polymerase) (PARP), and Nitrotyrosine

Immunohistochemical examination was performed as previously described [31], 4 days after DNBS administration. The sections were incubated overnight with the following primary antibodies: anti-CD4 ${ }^{+}$(Santa Cruz Biotechnology (SCB), 1:100 in PBS, v/v, sc-19641, D.B.A, Milan, Italy); anti-CD8 ${ }^{+}$(SCB, 1:100 in PBS, v/v, sc-1177, D.B.A, Milan, Italy); anti-ICAM-1 (SCB, 1:100 in PBS, v/v, sc-107, D.B.A, Milan, Italy), anti-P-selectin (1:100 in PBS, v/v, sc-8419 SCB, D.B.A, Milan, Italy), anti-PARP (1:100 in PBS, v/v, sc-8007 SCB, D.B.A, Milan, Italy), and anti-nitrotyrosine (1:200 in PBS, $v / v$, Millipore, D.B.A, Milan, Italy). All slices were washed with PBS and then treated as previously reported [32]. Briefly, slices were incubated with universal secondary antibody. Specific labeling was detected with a biotin- conjugated goat anti-rabbit IgG and avidin-biotin peroxidase complex (Vector).

Five stained sections from each mouse were scored in a blinded fashion and observed using a Leica DM6 microscope (Leica Microsystems SpA, Milan, Italy) following a typical procedure [33]. The histogram profile is related to the positive pixel intensity value obtained.

\subsection{Western Blots Analyses}

Cytosolic and nuclear proteins were extracted from colon tissues as previously described [28]. The behind primary antibodies were used: anti-TLR4 (SCB, 1:500, \#sc293072, D.B.A, Milan, Italy); anti-Myd88 (SCB; 1:500, \#sc-74532, D.B.A, Milan, Italy); anti-IKB- $\alpha$ (SCB, 1:500, \#sc-4094, D.B.A, Milan, Italy), anti-NF-kB (SCB; 1:500 \#sc8008, D.B.A, Milan, Italy), anti-Nrf2 (SCB, 1:500; \#A-10:sc-365949; D.B.A, Milan, Italy); anti-HO-1 (SCB, 1:500; \#sc-136960; D.B.A, Milan, Italy), in PBS with 5\% $w / v$ non-fat dried milk and $0.1 \%$ Tween-20 at $4{ }^{\circ} \mathrm{C} \mathrm{O} / \mathrm{N}$. Membranes were incubated with peroxidase-conjugated bovine anti-mouse IgG secondary antibody or peroxidase-conjugated goat anti-rabbit IgG (Jackson ImmunoResearch, West Grove, PA, USA; 1:2000) for $1 \mathrm{~h}$ at room temperature. Anti- $\beta$-actin or anti-lamin A/C (D.B.A, Milan, Italy) antibodies were used as controls. Protein expression was analyzed as previously reported [34]. 


\subsection{Cytokine Measurements}

In the colon tissues obtained after sacrifice, TNF- $\alpha$ (Ray Bio ELISA Kit Mouse TNFalpha, Norcross, GA, USA), IL-1 $\beta$, CCL2, and PGE2 (R\&D Systems, Milan, Italy) levels were evaluated using a colorimetric commercial kit [22].

\subsection{Statistical Analysis}

All values in the figures and text are expressed as mean \pm standard deviation (SD) of $\mathrm{N}$ observations. For the in vivo studies, $\mathrm{N}$ represents the number of animals studied. In experiments involving histology, the figures shown are representative of at least three experiments performed on different days on tissue sections collected from all animals in each group. The results were analyzed by one-way ANOVA followed by a Bonferroni post hoc test for multiple comparisons. A $p$-value of less than 0.05 was considered significant.

\section{Results}

\subsection{Effects of CV on Macroscopic Changes and Body Weight}

Macroscopic inspection of the colon showed no changes in the Sham and Sham $+C V$ groups mice. Animals treated with DNBS, on the other hand, showed a flaccid colon with liquid stools and in some cases, ulcerations with mucosal congestion. Oral treatment with $C V$ significantly reduced tissue inflammation and macroscopic signs (Figure 1A,B). Diarrhea observed mainly in mice of the DNBS group also led to a significant reduction in the body weight of these animals compared to the Sham group, while treatment with $C V$ was able to restore the weight loss induced by DNBS (Figure 1C).

(A)

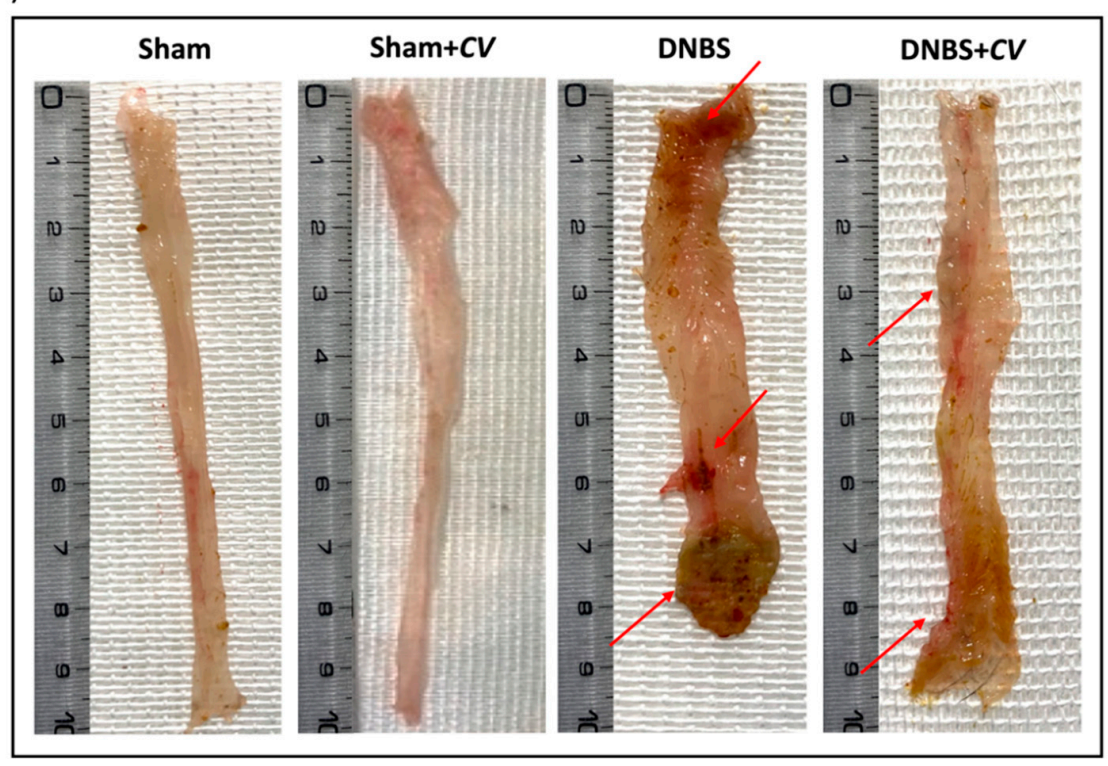

(B)

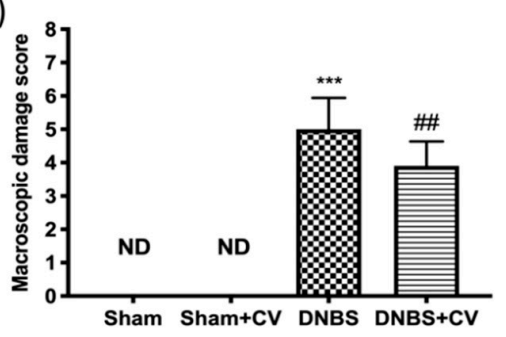

(C)

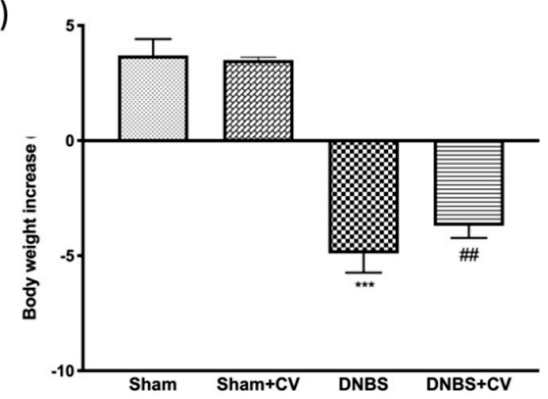

Figure 1. The effects of $C V$ on macroscopic damage and body weight after DNBS-injection. Macroscopic changes in Sham, Sham $+C V$, DNBS, DNBS $+C V$ groups (A). Macroscopic damage score was performed by two independent observers $(B)$. Body weight increase $(\mathbf{C})$. Values $=$ means $\pm \mathrm{SD}$ of 10 animals in each group; ${ }^{* * *} p<0.001$ vs. Sham; \#\# $p<0.01$ vs. DNBS.

\subsection{Effects of $\mathrm{CV}$ on Histological Colon Injury}

Microscopic analysis carried out on sections of colon tissue collected from mice treated with DNBS and stained with H\&E showed infiltration of inflammatory cells (mostly neutrophils), necrosis and edema (Figure 2C,E), compared to the tissues of the Sham and Sham $+C V$ groups in which no ulcer formation was observed (Figure 2A,B,D). Oral treatment with $C V$ reduced histological changes by reducing inflammation and the severity of colitis (Figure 2D,E). 
(A)

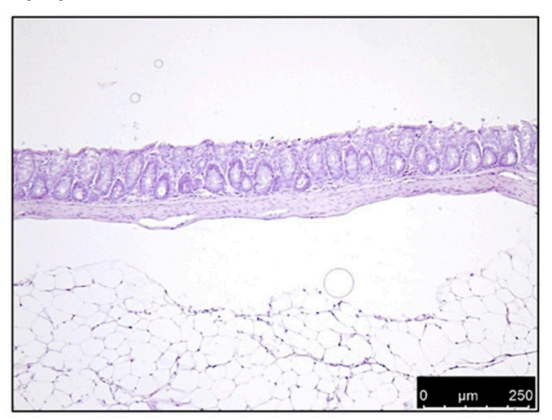

(D)

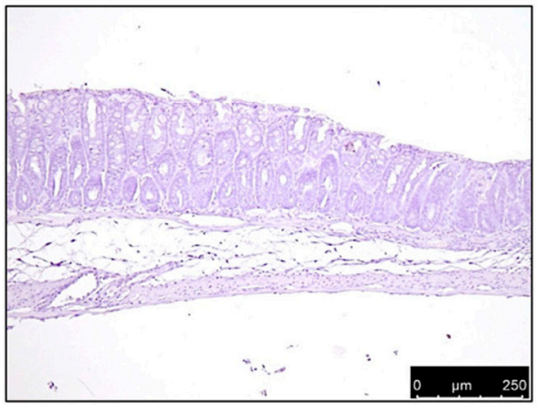

(B)

Sham $+C V$

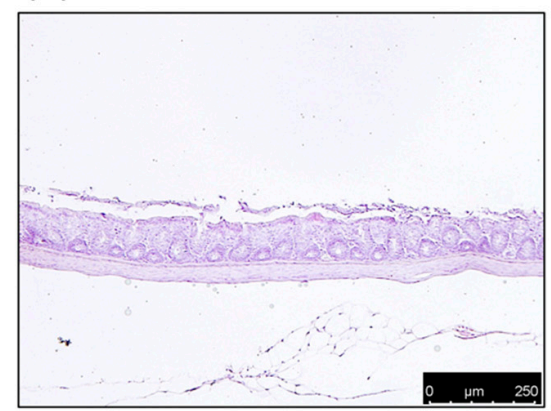

(C)

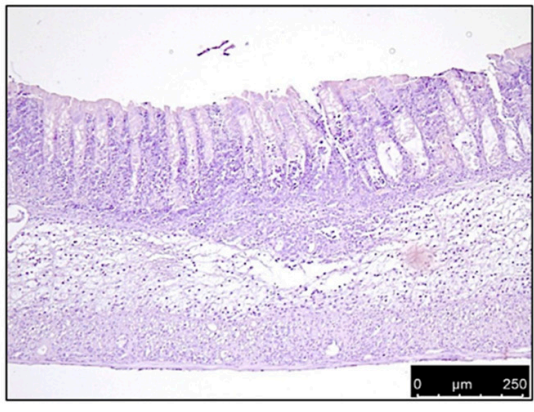

(E)

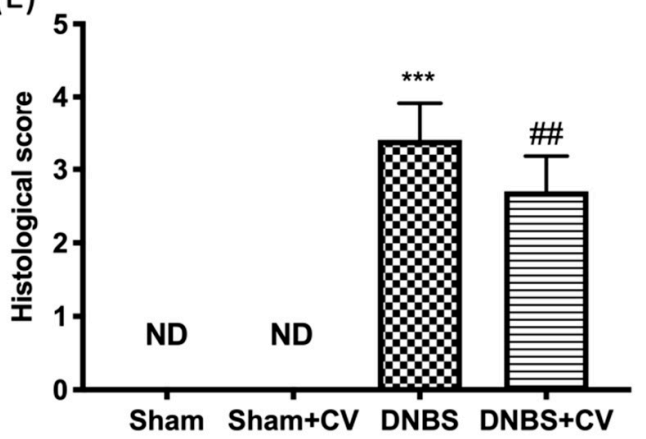

Figure 2. The effects of $C V$ on microscopic damage after DNBS-injection. Histological analysis was evaluated in Sham (A), Sham $+C V$ (B), DNBS (C), DNBS $+C V$ (D). The histological score was measured (E). Images are figurative of at least three independent experiments. Values $=$ means \pm SD of 5 animals in each group; ${ }^{* * *} p<0.001$ vs. Sham; \#\# $p<0.01$ vs. DNBS.

\subsection{Effects of $C V$ on Inflammatory Pathway}

In order to study how $C V$ acted on inflammatory processes we evaluated the variations of TLR4 and consequently the expression of Myd88 and NF-kB pathway. By the immunohistochemical analysis we observed an increase in the expression of TLR4 in the colon sections taken from the mice treated with DNBS (Figure 3B,D), compared to the control group (Figure 3A,D). On the contrary, treatment with $C V$ significantly limited the expression of this receptor (Figure 3C,D). Subsequently, owing to Western blot analyses, we observed how the activation of TLR4 also led to changes in the Myd88 (Figure 3E, $\mathrm{E}^{\prime}$ ), IKB- $\alpha$ (Figure 3F, $\mathrm{F}^{\prime}$ ), and NF-kB (Figure $3 \mathrm{G}, \mathrm{G}^{\prime}$ ) proteins. In particular, increase in the expression of $\mathrm{Myd} 88$, the degradation of IKB- $\alpha$, and the consequent nuclear translocation of NF-kB were observed in the DNBS group, while the treatment with $C V$ was able to prevent this inflammatory phenomena. 
(A)

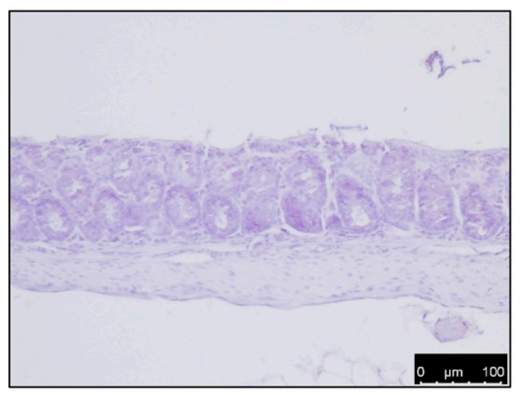

(C)

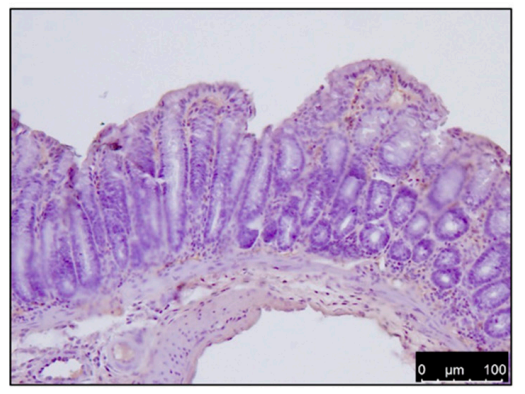

(B)

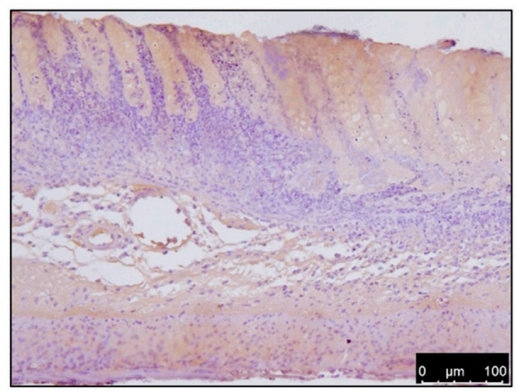

(D)

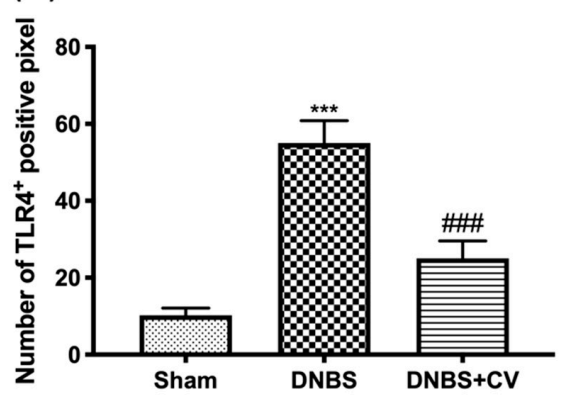

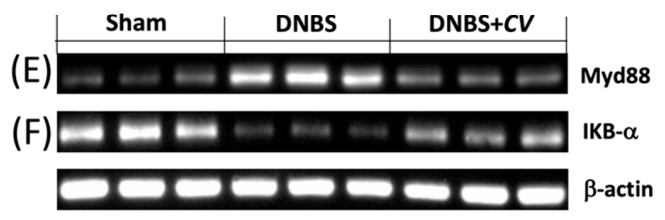

$\left(E^{\prime}\right)$

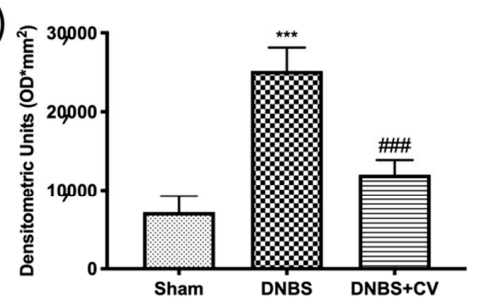

$\left(F^{\prime}\right)$
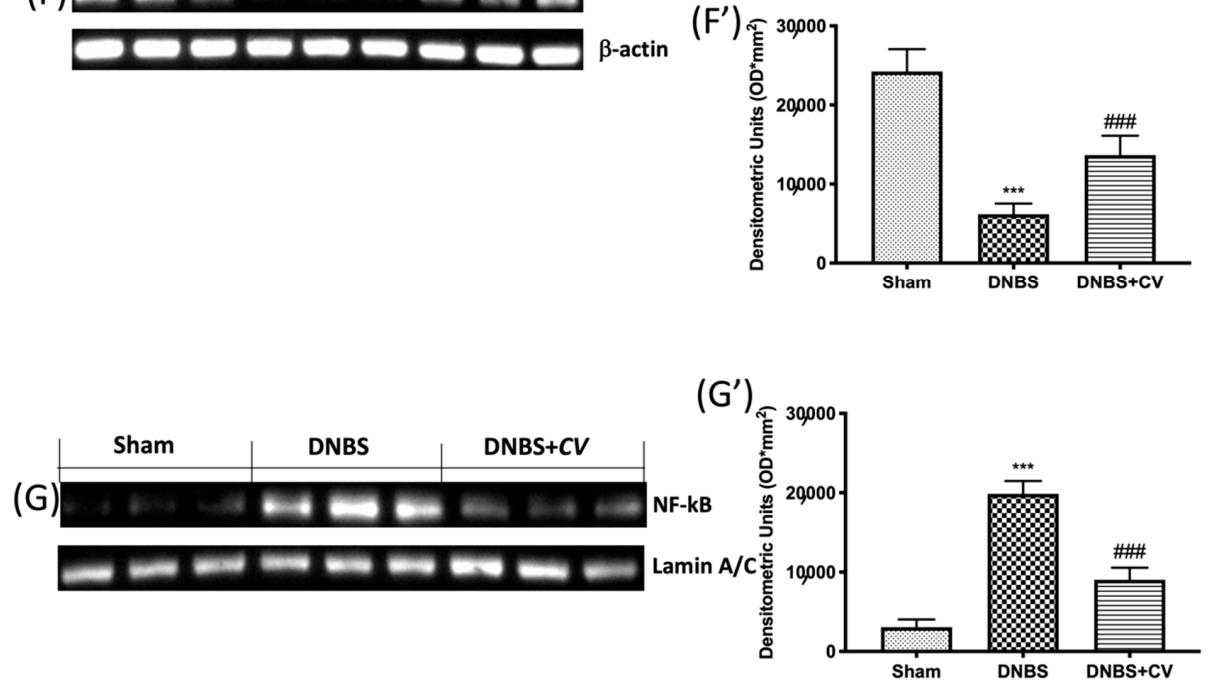

Figure 3. The effects of $C V$ on TLR4, Myd88 and NF-kB pathway expression after DNBS-injection. Immunohistochemistry for TLR4 was evaluated in Sham (A), DNBS (B) and DNBS+CV (C). The results are expressed as number of TLR $4^{+}$positive pixel (D). Images are figurative of at least three independent experiments. Western blots for Myd88, IKB- $\alpha$, and NF-kB. Representative Western blots for cytoplasmic Myd88 (E, $\left.\mathbf{E}^{\prime}\right)$, IKB- $\alpha$ degradation $\left(\mathbf{F}, \mathbf{F}^{\prime}\right)$, nuclear NF-kB translocation $\left(\mathbf{G}, \mathbf{G}^{\prime}\right)$ expression were performed. A demonstrative blot of lysates ( 5 animals/group), with a densitometric analysis for all animals, is shown $\left(\mathbf{E}^{\prime}-\mathbf{G}^{\prime}\right)$. Values $=$ means $\pm \mathrm{SD}$ of 5 animals in each group. ${ }^{* * *} p<0.001 \mathrm{vs}$. Sham; \#\# $p<0.001$ vs. DNBS. 


\subsection{Effects of $C V$ on $M P O, M D A$, and Pro-Inflammatory Mediators}

Colon damage induced by DNBS was also illustrated by the increase in neutrophilic infiltration in the colon measured by the activity of MPO (Figure 4A) and by the increase in MDA levels (Figure 4B), compared to the control group. Furthermore, by ELISA tests we measured the levels of other pro-inflammatory mediators involved in inflammation of the colon such as CCL2 (Figure 4C), PGE2 (Figure 4D), IL-1 $\beta$ (Figure 4E), and TNF- $\alpha$ (Figure $4 \mathrm{~F}$ ). The results showed a significant increase of these mediators in the tissues of the group DNBS, compared to the Sham group. Oral treatment with $C V$ significantly reduced the accumulation of neutrophils in the colon, lipid peroxidation, the levels of the pro-inflammatory mediators CCL2, PGE2, and of the cytokines IL- $1 \beta$ and TNF- $\alpha$.

Significant positive staining was observed for $\mathrm{CD}^{+}$and $\mathrm{CD}^{+}$in colon tissues of animals treated with DNBS, compared to the Sham group where no positive staining was evident. $\mathrm{CV}$ treatment reduced positive staining for both $\mathrm{CD}^{+}$and $\mathrm{CD} 8^{+}$(Figure $5 \mathrm{~A}-\mathrm{D}$ for $\mathrm{CD}^{+}$; Figure $5 \mathrm{E}-\mathrm{H}$ for $\mathrm{CD}^{+}$). The increase in these cells led to an increase in the expression of P-selectin and ICAM1 in the colon of mice of the DNBS group, compared to the control group. Moreover, in this case the administration of $C V$ led to a reduction of the positive staining for both adhesion molecules (Figure 6A-D for P-selectin; Figure 6E-H for ICAM1).

(A)

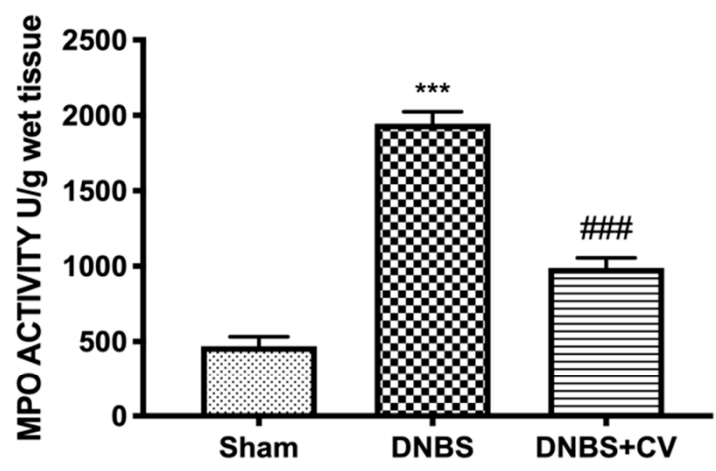

(C)

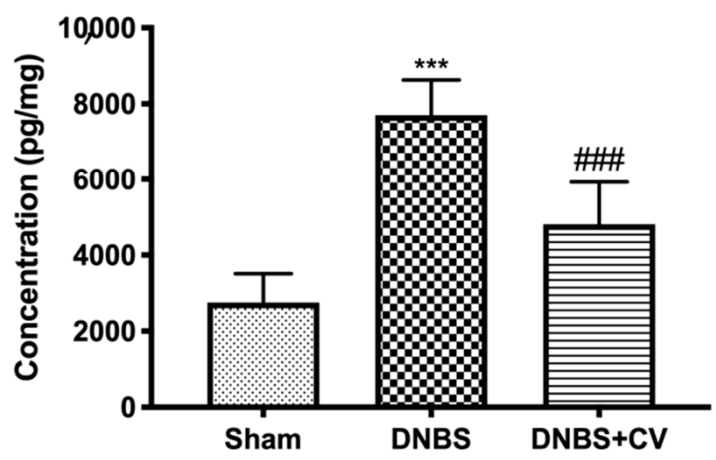

(B)

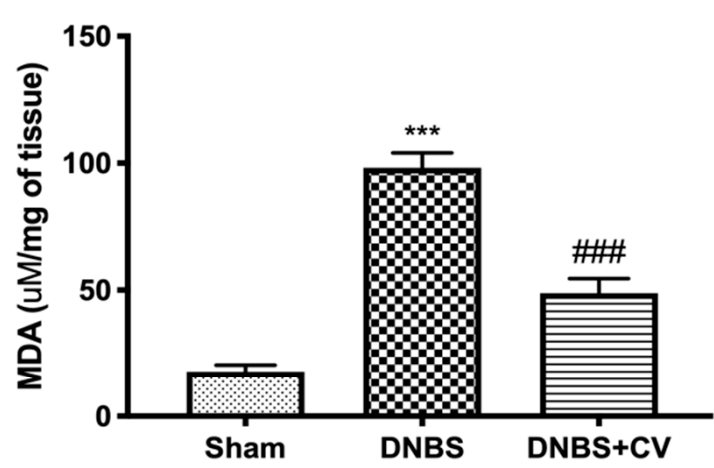

(D)

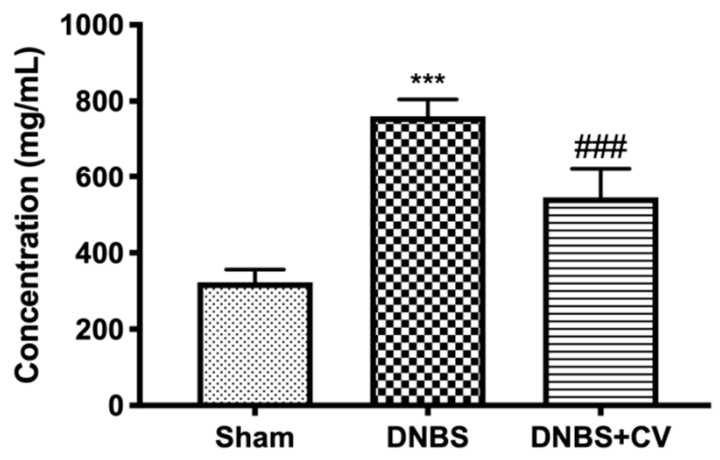

Figure 4. Cont. 
(E)

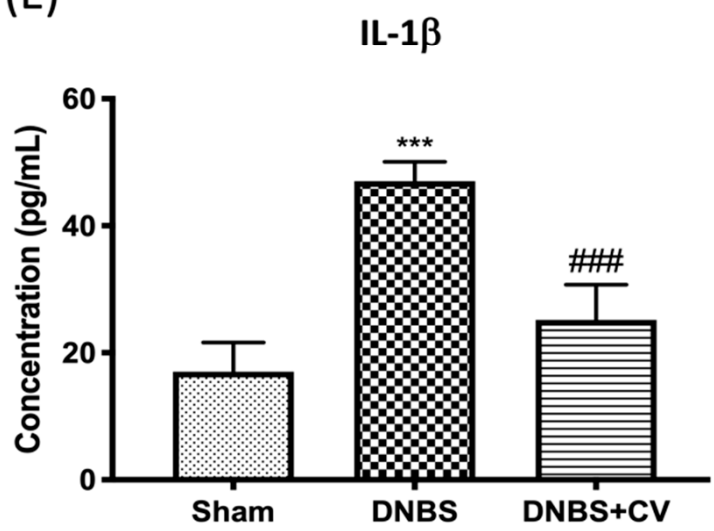

(F)

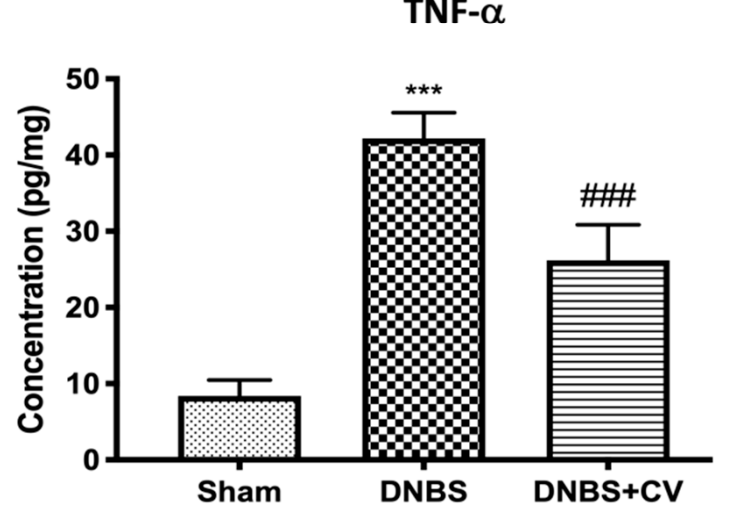

Figure 4. The effects of $C V$ on MPO, MDA, CCL2, PGE2, IL-1 $\beta$, and TNF- $\alpha$ after DNBS-injection. MPO (A) and MDA (B) assays were performed for neutrophil infiltration and lipid peroxidation. MPO (A) and MDA (B) assays were performed for neutrophil infiltration and lipid peroxidation. The concentrations of CCL2 (C), PGE2 (D), IL-1 $\beta$ (E), and TNF- $\alpha$ (F) in the colon collected after 4 days from the induction of colitis were evaluated using ELISA kits. Values $=$ means \pm SD of 5 animals in each group; $^{* * *} p<0.001$ vs. Sham; \#\#\# $p<0.001$ vs. DNBS.

\subsection{Effects of $\mathrm{CV}$ on $\mathrm{CD}^{+}, \mathrm{CD}^{+}$, and Adhesion Molecules}

$\mathrm{CD}^{+}$and $\mathrm{CD}^{+} \mathrm{T}$ cells are also important mediators of inflammation in the colon, which together with cytokines lead to an increase in adhesion molecules such as P-selectin and ICAM1.

(A)

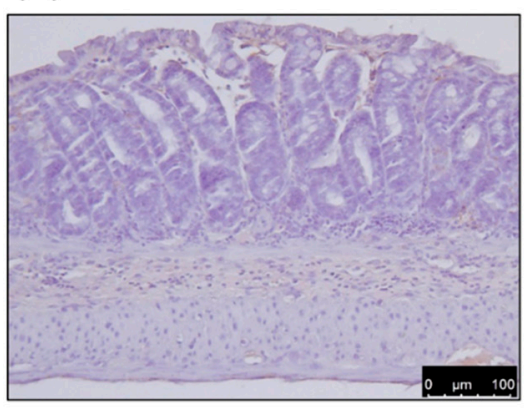

(C)

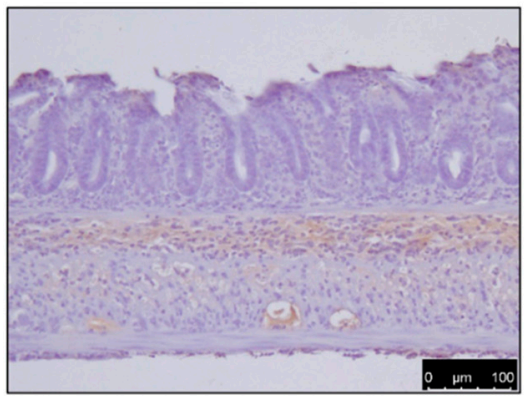

(B)

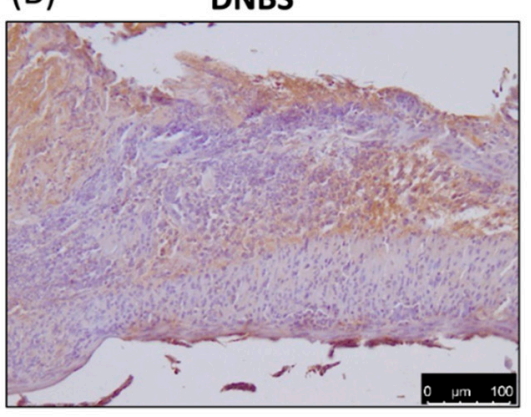

(D)

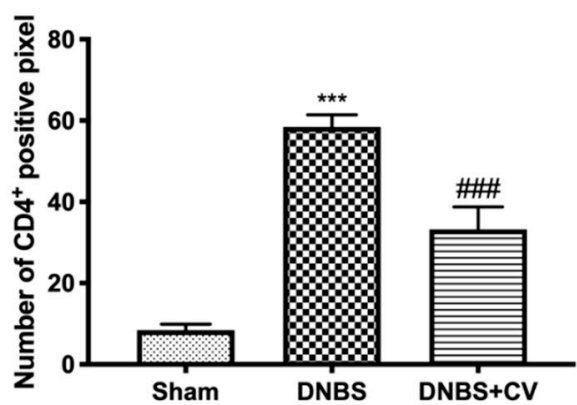

Figure 5. Cont. 
(E)

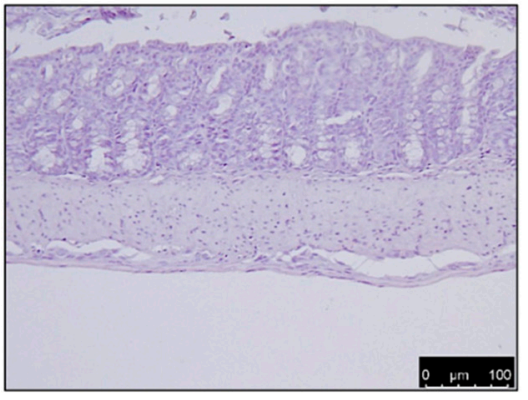

(G)

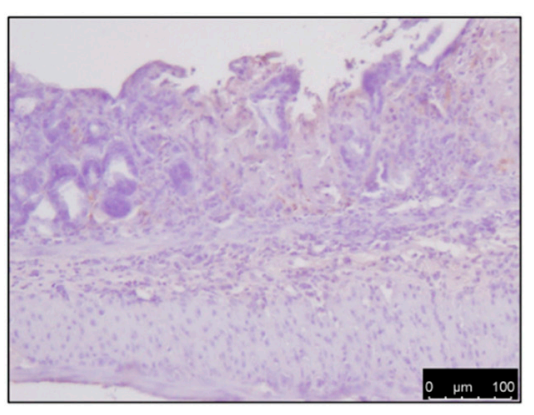

(F) DNBS

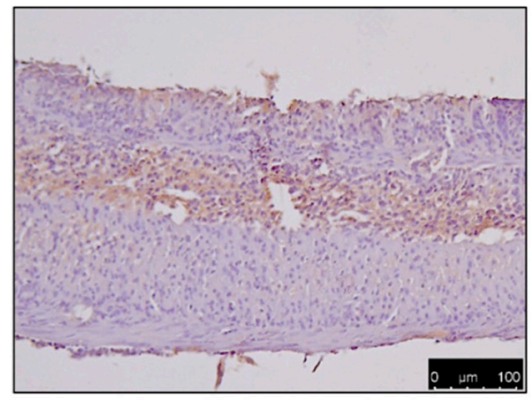

(H)

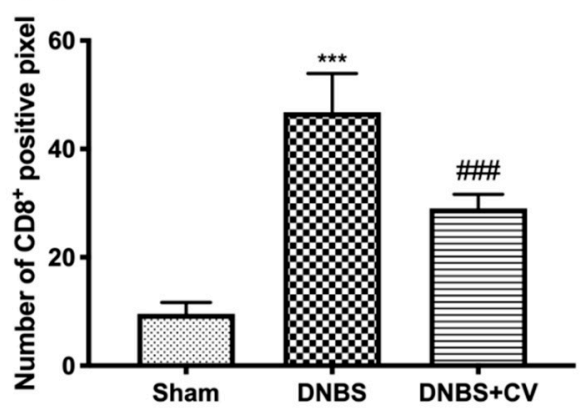

Figure 5. The effects of $\mathrm{CV}$ on $\mathrm{CD}^{+}$and $\mathrm{CD} 8^{+}$expression after DNBS-injection. Immunohistochemistry for CD4+ was evaluated in Sham (A), DNBS (B) and DNBS+CV (C). The results are expressed as number of $\mathrm{CD}^{+}$positive pixel (D). The same analysis was performed for $\mathrm{CD}^{+}$on the colon sections of the Sham $(\mathrm{E})$, DNBS $(\mathrm{F}), \mathrm{DNBS}+\mathrm{CV}(\mathrm{G})$ groups. The results are expressed as number of $\mathrm{CD}^{+}$positive pixel $(\mathbf{H})$. The Images are figurative of at least three independent experiments. Values $=$ means \pm SD of 5 animals in each group. ${ }^{* * *} p<0.001$ vs. Sham; \#\#\# $p<0.001$ vs. DNBS.

A)

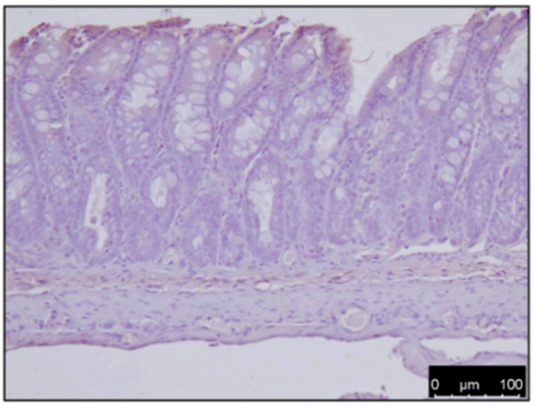

C)

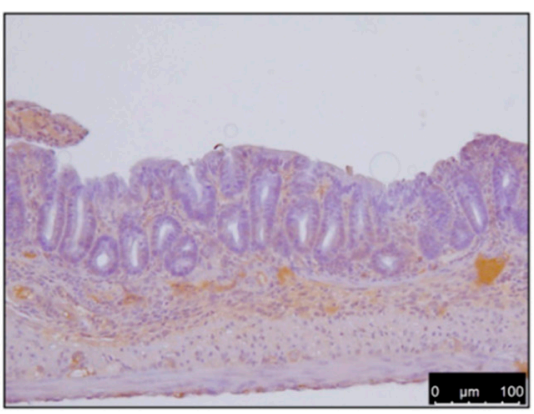

B)

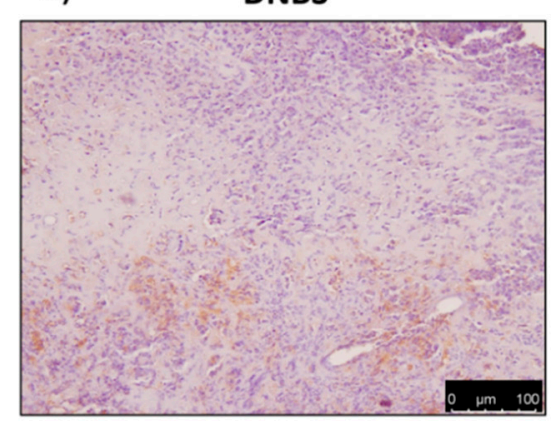

D)

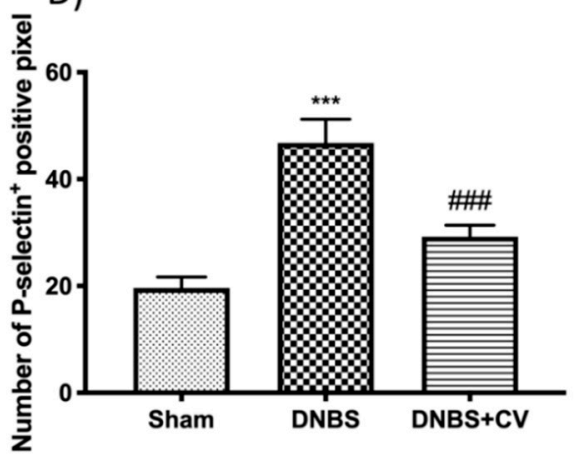

Figure 6. Cont. 
E)

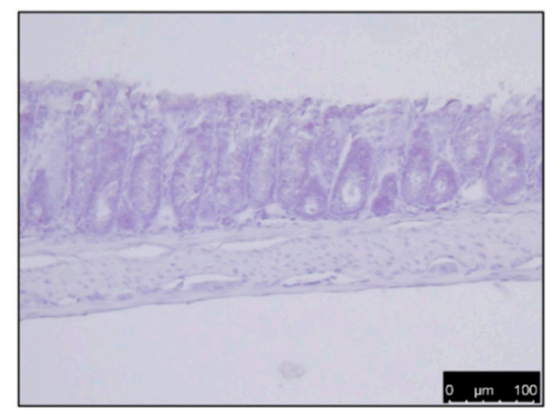

G)

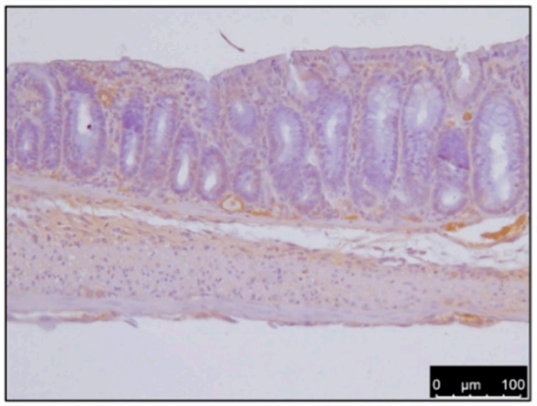

F)

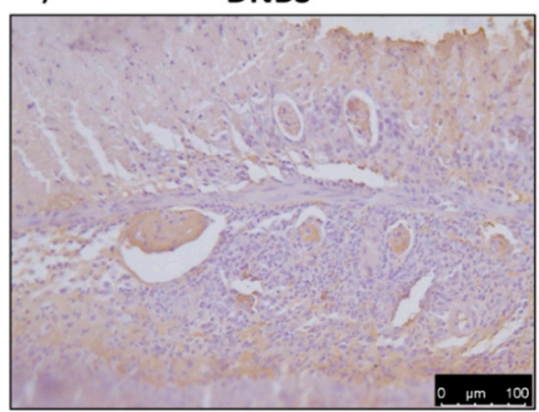

H)

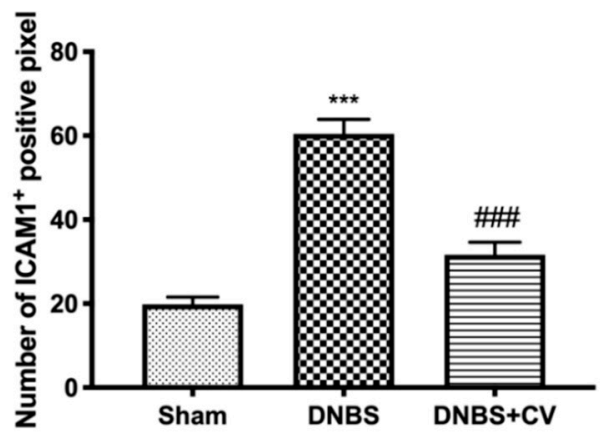

Figure 6. The effects of $C V$ on P-selectin and ICAM1 expression after DNBS-injection. Immunohistochemistry for P-selectin was evaluated in Sham (A), DNBS (B) and DNBS +CV (C). The results are expressed as number of $\mathrm{P}_{\text {-selectin }}{ }^{+}$positive pixel (D). The same analysis was performed for ICAM1 on the colon sections of the Sham (E), DNBS (F), DNBS+CV (G) groups. The results are expressed as number of ICAM1 ${ }^{+}$positive pixel $(\mathbf{H})$. The Images are figurative of at least three independent experiments. Values $=$ means \pm SD of 5 animals in each group. ${ }^{* * *} p<0.001 \mathrm{vs}$. Sham; $\# \#$ \# $<0.001$ vs. DNBS.

\subsection{Effects of $C V$ on Nitrotyrosine and PARP Expression}

To study the effect of $C V$ on nitrosative stress and on PARP hyperactivation we performed an immunohistochemical analysis on the colon sections. This analysis showed a significant positive staining in the colon of the mice of the DNBS group for both nitrotyrosine and PARP, unlike the Sham group where no staining was highlighted. Treatment with $\mathrm{CV}$ was able to reduce nitrosative stress and PARP hyperactivation in the colon showing less positive staining than the vehicle group (Figure 7A-D for Nitrotyrosine; Figure 7E-H for PARP). 


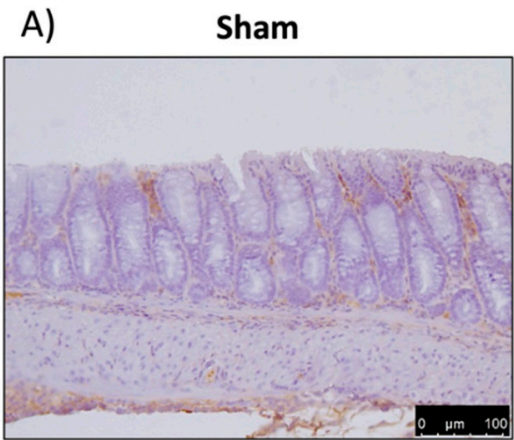

B) DNBS

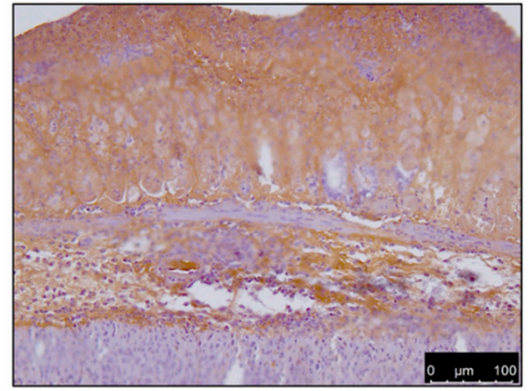

C)

DNBS+CV
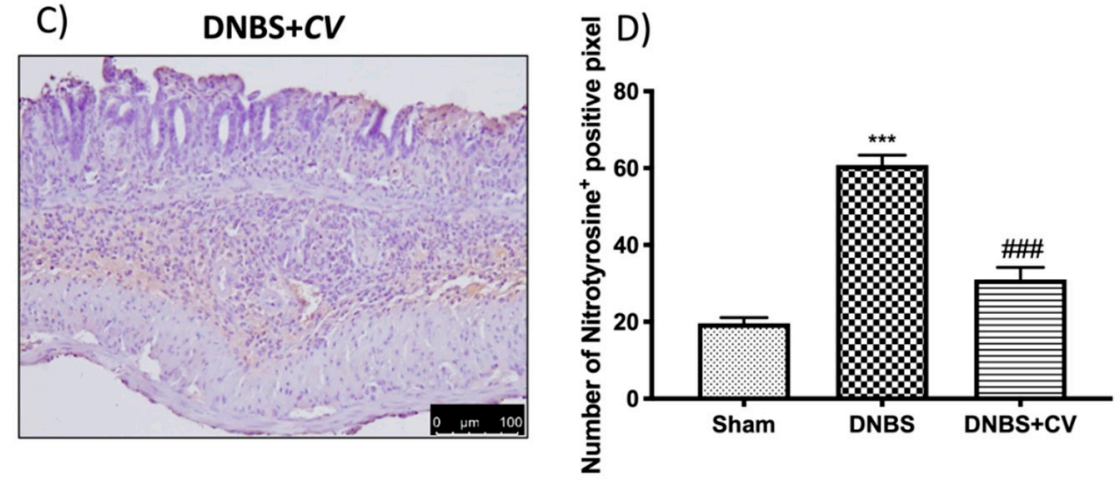

E)

Sham

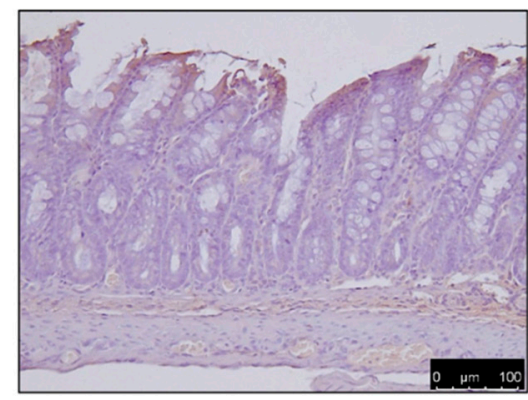

G)

DNBS+CV

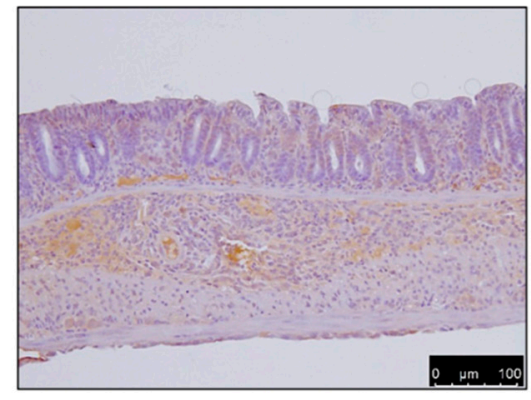

F)

DNBS

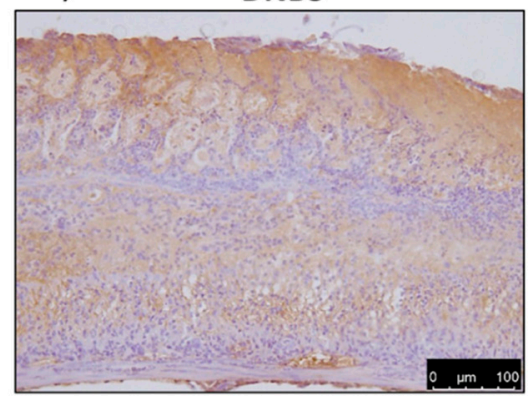

H)

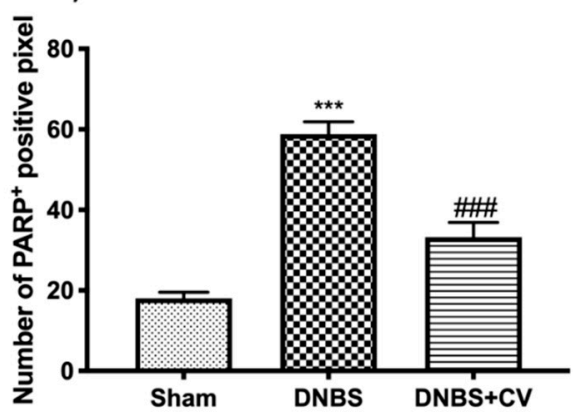

Figure 7. The effects of $C V$ on nitrotyrosine and PARP expression after DNBS-injection. Immunohistochemistry for nitrotyrosine was evaluated in Sham (A), DNBS (B) and DNBS +CV (C). The results are expressed as number of nitrotyrosine ${ }^{+}$positive pixel (D). The same analysis was performed for PARP on the colon sections of the Sham (E), DNBS (F), DNBS $+C V(\mathbf{G})$ groups. The results are expressed as number of $\mathrm{PARP}^{+}$positive pixel $(\mathbf{H})$. The images are figurative of at least three independent experiments. Values $=$ means \pm SD of 5 animals in each group. ${ }^{* * *} p<0.001$ vs. Sham; \#\#\# $p<0.001$ vs. DNBS. 


\subsection{Effects of CV on Nrf2/HO-1 Pathway}

As ROS are known to play an important role in potentiating inflammation, we assessed by Western blot analysis whether $C V$ treatment can modulate oxidative processes through the Nrf2/HO-1 pathway. On day 4, $C V$ administration significantly increased Nrf2 expression (Figure 8A, $\mathrm{A}^{\prime}$ ). Furthermore, based on the observed increase in Nrf2 expression, we also evaluated the expression of HO-1, another important enzyme involved in the oxidative stress pathway. The results obtained from our experiments also showed a significant increase in HO-1 expression after treatment with $C V$ (Figure 8B, $\mathrm{B}^{\prime}$ ).

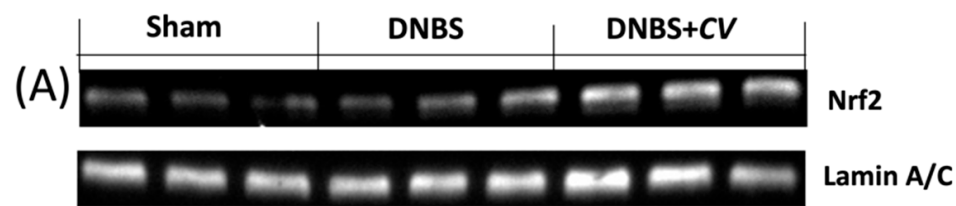

$\left(A^{\prime}\right)$

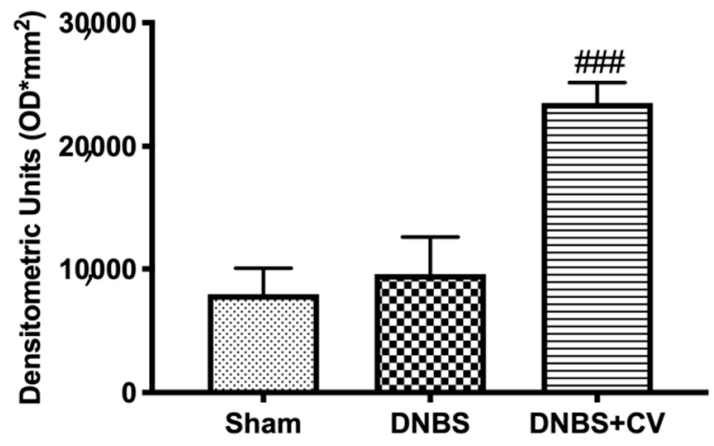

(B)

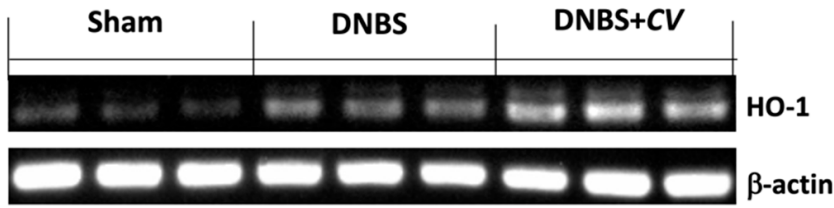

$\left(B^{\prime}\right)$

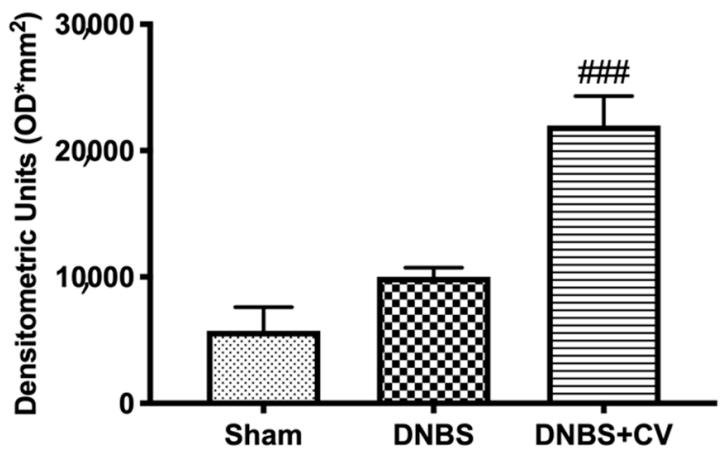

Figure 8. The effects of $\mathrm{CV}$ on Nrf2/HO-1 pathway expression after DNBS-injection. Representative Western blots for nuclear Nrf2 $\left(\mathbf{A}, \mathbf{A}^{\prime}\right)$ and cytoplasmic HO-1 $\left(\mathbf{B}, \mathbf{B}^{\prime}\right)$ expression were performed. A demonstrative blot of lysates ( 5 animals/group), with a densitometric analysis for all animals, is shown $\left(\mathbf{A}^{\prime}, \mathbf{B}^{\prime}\right)$. Values $=$ means \pm SD of 5 animals in each group. \#\# $p<0.001$ vs. DNBS.

\section{Discussions}

IBD are inflammatory bowel diseases characterized by dysfunction of the immune response of the mucosa, abnormal production of pro-inflammatory cytokines such as TNF- $\alpha$ 
and IL-1, increased expression of adhesion molecules and infiltrated cell, imbalance of the redox balance that eventually led to epithelial cell apoptosis and mucosal damage [35-37]. A mechanism responsible for the development of the inflammatory reaction in colitis is the activation of TLR4. The increase of the expression of TLR4 and the increase of the production of CCL2, COX-2, PGE2, and TNF- $\alpha$ compromise the regeneration of the mucosa, with consequent tissue damage that over time can lead to the development of cancer of the colon [38,39]. Recent studies have highlighted the ability of extracts from $C V$ to act as antiinflammatory agents with cytotoxic properties against endothelial cells and breast cancer cells. This protective action has been linked to the ability of these extracts to reduce the activation of TLR4 and consequently limit the inflammatory response [40-42]. In addition, dietary interventions with $C V$ have been shown to modulate mitochondrial production of ROS and oxidative damage repair in numerous chronic diseases [25,43].

Therefore, our hypothesis was that $C V$ could act by modulating TLR4 on inflammatory processes and oxidative stress characteristic of IBD in an animal model of DNBS-induced colitis. To understand the molecular mechanisms involved in the effects of $C V$ on inflammation of the DNBS colon, we studied the expression of TLR4 by immunohistochemical analysis. A significant increase in TLR4 expression was observed in mice treated with DNBS compared to control mice, while oral administration of $C V$ was able to significantly reduce the expression of this receptor. To confirm the involvement of TLR4 and the ability of $C V$ to interfere with the cascade of the TLR4 signal, we evaluated the expression of Myd88 and the NF-kB pathway by Western blot analysis. The results obtained showed a significant increase of Myd88 in mice in the vehicle group which led to IKB- $\alpha$ degradation and nuclear translocation to NF-kB. Treatment with $C V$ has significantly limited these effects.

In addition, during inflammation of the colon several pro-inflammatory mediators are released following transcriptional induction of the NF-kB pathway; therefore, we checked whether treatment with $C V$ modulated the secretion of pro-inflammatory agents such as TNF- $\alpha$, IL-1 $\beta$, CCL2, and PGE2 by measuring their levels using an ELISA kit. The results we obtained showed that the activation of the NF-kB pathway led to the significant increase of these pro-inflammatory mediators, while the treatment with $C V$ was able to reduce the levels of TNF- $\alpha$, IL-1 $\beta$, CCL2, and PGE2 significantly. Other known mediators of inflammation in IBD are $\mathrm{CD}^{+}$and $\mathrm{CD}^{+} \mathrm{T}$ cells. These active cells were found in the peripheral blood and intestinal mucosa of subjects with IBD [44-46]. An abnormal immune response with excessive activation of $\mathrm{CD}^{+}$and $\mathrm{CD}^{+} \mathrm{T}$ cells was also found in our study in mice treated with DNBS. Treatment with $C V$ was able to limit the activation of these cells, contributing together to the reduction of the inflammatory process. The increase in proinflammatory mediators at the intestinal level in turn causes an increase in the expression of adhesion molecules such as selectins and addressins that stimulate the infiltration of leukocytes into the intestinal mucosa [47]. In accordance with the data in the literature, we observed significantly increased levels of P-Selectin and ICAM1 in the group of animals treated with DNBS, probably due to the increase in intestinal lesion that was highlighted by our macroscopic and microscopic analyses. Treatment with $C V$ significantly abolished the expression of both proteins. In addition, the lower expression of adhesion molecules in the colon tissue of mice treated with $C V$ is, at least in part, related to the reduction of polymorphonuclear number (PMN), as shown by the activity of MPO, and the reduction of tissue damage and ulcer formation. As noted in several studies, tissue damage to the colon is not only due to an abnormal response of the immune system and therefore to the activation of inflammatory processes, but also to an increase in the release of ROS and redox imbalance [48]. In particular, the increase in ROS levels can negatively affect proteins, nucleic acids, and lipids through the instigation of fragmentation products that lead to enzymatic alterations, release of lipid peroxides, and formation of DNA strand break products [49]. Being able to act on the levels of ROS not only means restoring the redox balance between antioxidant enzymes and not, but also decreasing nitrosative stress and hyperactivation of Poly ADP-ribose (PAR) [50]. Here, we have clearly shown that $C V$ inhibits the appearance of nitrotyrosine and PARP staining in the inflamed colon, 
suggesting that $C V$ can act through several pathways in addition to the inflammatory one. In particular, we studied an important antioxidant pathway, Nrf2/HO-1, which seems to be related to NF-kB signaling [51]. Nrf2 is the main transcriptional regulator of antioxidant proteins that translates into the nucleus and promotes the expression of $\mathrm{HO}-$ 1 after cell damage $[52,53]$. Our data have highlighted the ability of $C V$ to activate Nrf2 and consequently also HO-1 and therefore act on antioxidant defense systems important for the reduction of oxidative stress induced by DNBS.

\section{Conclusions}

In conclusion, we can say that $C V$ has shown to have both anti-inflammatory and antioxidant roles in the model of colitis induced by DNBS. Therefore, it could be used as a dietary supplement for the treatment of IBD. However, further studies are needed to define the mechanism of action well. Being a natural compound with both anti-inflammatory and antioxidant properties, it would be interesting to understand if its beneficial action is really related to TLR4 or if it acts through other pathways such as Nrf2 (Figure 9).

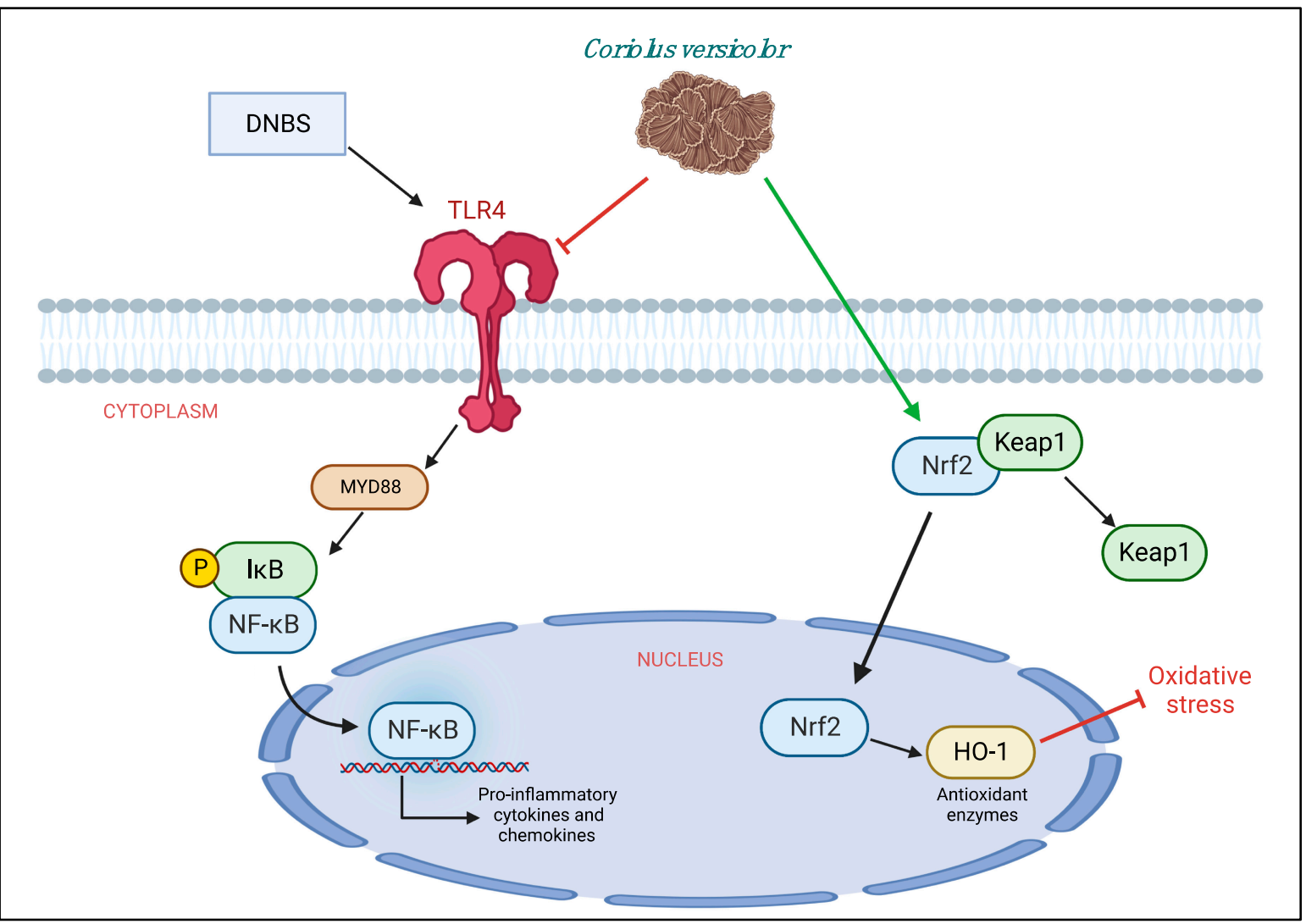

Figure 9. Protective effects of Coriolus versicolor on different pathways.

Author Contributions: Conceptualization, R.S., R.D.P. and V.C.; methodology, R.S., R.F., R.D., S.M. and M.L.O.; software, M.C.; validation, R.S., D.I., R.D.P., V.C. and S.C.; formal analysis, R.S. and R.F.; investigation, R.S., D.I. and R.D.; data curation, R.S.; writing — original draft preparation, D.I. and R.F.; writing-review and editing, R.S., T.G., R.F. and A.T.S.; supervision, R.D.P., S.C. and V.C. All authors have read and agreed to the published version of the manuscript.

Funding: This research received no external funding.

Institutional Review Board Statement: The Review Board for the care of animals of the University of Messina approved the study (ethical protocol code: $n^{\circ}$ 89126.24/2021). We respected the legislation for the protection of laboratory animals (D.Lgs 2014/26 and EU Directive 2010/63).

Informed Consent Statement: Not applicable. 
Data Availability Statement: For a rule of our laboratory the datasets used in the current study are available from the corresponding author (dipaolar@unime.it) on reasonable request.

Acknowledgments: Authors recognize helpful discussion with Marjaneh Seifi, Mycology Research Laboratories Ltd. (UK), and would like to thank Valentina Malvagni for editorial support with the manuscript.

Conflicts of Interest: The authors declare no conflict of interest.

\section{References}

1. Gajendran, M.; Loganathan, P.; Jimenez, G.; Catinella, A.P.; Ng, N.; Umapathy, C.; Ziade, N.; Hashash, J.G. A comprehensive review and update on ulcerative colitis. Dis. Mon. 2019, 65, 100851. [CrossRef]

2. Ananthakrishnan, A.N.; Bernstein, C.N.; Iliopoulos, D.; Macpherson, A.; Neurath, M.F.; Ali, R.A.R.; Vavricka, S.R.; Fiocchi, C. Environmental triggers in IBD: A review of progress and evidence. Nat. Rev. Gastroenterol. Hepatol. 2018, 15, 39-49. [CrossRef]

3. Thomas, H. IBD: Functional characterization of an IBD risk gene. Nat. Rev. Gastroenterol. Hepatol. 2018, 15, 190-191. [CrossRef]

4. Turner, J.R. Intestinal mucosal barrier function in health and disease. Nat. Rev. Immunol. 2009, 9, 799-809. [CrossRef]

5. Frenkel, S.; Bernstein, C.N.; Sargent, M.; Jiang, W.; Kuang, Q.; Xu, W.; Hu, P. Copy number variation-based gene set analysis reveals cytokine signalling pathways associated with psychiatric comorbidity in patients with inflammatory bowel disease. Genomics 2020, 112, 683-693. [CrossRef]

6. $\quad$ Fang, J.; Seki, T.; Tsukamoto, T.; Qin, H.; Yin, H.; Liao, L.; Nakamura, H.; Maeda, H. Protection from inflammatory bowel disease and colitis-associated carcinogenesis with 4-vinyl-2,6-dimethoxyphenol (canolol) involves suppression of oxidative stress and inflammatory cytokines. Carcinogenesis 2013, 34, 2833-2841. [CrossRef]

7. Pawar, P.; Gilda, S.; Sharma, S.; Jagtap, S.; Paradkar, A.; Mahadik, K.; Ranjekar, P.; Harsulkar, A. Rectal gel application of Withania somnifera root extract expounds anti-inflammatory and muco-restorative activity in TNBS-induced inflammatory bowel disease BMC Complement. Altern. Med. 2011, 11, 34. [CrossRef]

8. Achitei, D.; Ciobica, A.; Balan, G.; Gologan, E.; Stanciu, C.; Stefanescu, G. Different profile of peripheral antioxidant enzymes and lipid peroxidation in active and non-active inflammatory bowel disease patients. Dig. Dis. Sci. 2013, 58, 1244-1249. [CrossRef]

9. Cadirci, E.; Suleyman, H.; Aksoy, H.; Halici, Z.; Ozgen, U.; Koc, A.; Ozturk, N. Effects of Onosma armeniacum root extract on ethanol-induced oxidative stress in stomach tissue of rats. Chem. Biol. Interact. 2007, 170, 40-48. [CrossRef]

10. Moura, F.A.; de Andrade, K.Q.; Dos Santos, J.C.F.; Araujo, O.R.P.; Goulart, M.O.F. Antioxidant therapy for treatment of inflammatory bowel disease: Does it work? Redox Biol. 2015, 6, 617-639. [CrossRef]

11. Rutgeerts, P.; Vermeire, S.; van Assche, G. Biological therapies for inflammatory bowel diseases. Gastroenterology 2009, 136, 1182-1197. [CrossRef]

12. Privitera, G.; Pugliese, D.; Rapaccini, G.L.; Gasbarrini, A.; Armuzzi, A.; Guidi, L. Predictors and Early Markers of Response to Biological Therapies in Inflammatory Bowel Diseases. J. Clin. Med. 2021, 10, 853. [CrossRef]

13. Piechota-Polanczyk, A.; Fichna, J. Review article: The role of oxidative stress in pathogenesis and treatment of inflammatory bowel diseases. Naunyn Schmiedebergs Arch. Pharm. 2014, 387, 605-620. [CrossRef]

14. Rapa, S.F.; di Paola, R.; Cordaro, M.; Siracusa, R.; D’Amico, R.; Fusco, R.; Autore, G.; Cuzzocrea, S.; Stuppner, H.; Marzocco, S. Plumericin Protects against Experimental Inflammatory Bowel Disease by Restoring Intestinal Barrier Function and Reducing Apoptosis. Biomedicines 2021, 9, 67. [CrossRef]

15. Dziabowska-Grabias, K.; Sztanke, M.; Zajac, P.; Celejewski, M.; Kurek, K.; Szkutnicki, S.; Korga, P.; Bulikowski, W.; Sztanke, K. Antioxidant Therapy in Inflammatory Bowel Diseases. Antioxidants 2021, 10, 412. [CrossRef]

16. Elsayed, E.A.; el Enshasy, H.; Wadaan, M.A.; Aziz, R. Mushrooms: A potential natural source of anti-inflammatory compounds for medical applications. Mediat. Inflamm. 2014, 2014, 805841. [CrossRef]

17. Paterson, R.R.; Lima, N. Biomedical effects of mushrooms with emphasis on pure compounds. Biomed. J. 2014, 37, 357-368. [CrossRef]

18. Wasser, S.P. Medicinal mushroom science: Current perspectives, advances, evidences, and challenges. Biomed. J. 2014, 37, 345-356. [CrossRef]

19. Komura, D.L.; Ruthes, A.C.; Carbonero, E.R.; Gorin, P.A.; Iacomini, M. Water-soluble polysaccharides from Pleurotus ostreatus var. florida mycelial biomass. Int. J. Biol. Macromol. 2014, 70, 354-359. [CrossRef]

20. Fang, X.; Jiang, Y.; Ji, H.; Zhao, L.; Xiao, W.; Wang, Z.; Ding, G. The Synergistic Beneficial Effects of Ginkgo Flavonoid and Coriolus versicolor Polysaccharide for Memory Improvements in a Mouse Model of Dementia. Evid.-Based Complement. Altern. Med. 2015, 2015, 128394. [CrossRef]

21. D'Amico, R.; Trovato Salinaro, A.; Fusco, R.; Cordaro, M.; Impellizzeri, D.; Scuto, M.; Ontario, M.L.; Lo Dico, G.; Cuzzocrea, S.; Di Paola, R.; et al. Hericium erinaceus and Coriolus versicolor Modulate Molecular and Biochemical Changes after Traumatic Brain Injury. Antioxidants 2021, 10, 898. [CrossRef]

22. Peritore, A.F.; D'Amico, R.; Cordaro, M.; Siracusa, R.; Fusco, R.; Gugliandolo, E.; Genovese, T.; Crupi, R.; Di Paola, R.; Cuzzocrea, S.; et al. PEA/Polydatin: Anti-Inflammatory and Antioxidant Approach to Counteract DNBS-Induced Colitis. Antioxidants 2021, 10, 464. [CrossRef] [PubMed]

23. Monro, J.A. Treatment of cancer with mushroom products. Arch. Environ. Health 2003, 58, 533-537. [CrossRef] 
24. Tsai, Y.C.; Lin, Y.C.; Huang, C.C.; Villaflores, O.B.; Wu, T.Y.; Huang, S.M.; Chin, T.Y. Hericium erinaceus Mycelium and Its Isolated Compound, Erinacine A, Ameliorate High-Fat High-Sucrose Diet-Induced Metabolic Dysfunction and Spatial Learning Deficits in Aging Mice. J. Med. Food 2019, 22, 469-478. [CrossRef] [PubMed]

25. Trovato, A.; Siracusa, R.; Di Paola, R.; Scuto, M.; Fronte, V.; Koverech, G.; Luca, M.; Serra, A.; Toscano, M.A.; Petralia, A.; et al. Redox modulation of cellular stress response and lipoxin A4 expression by Coriolus versicolor in rat brain: Relevance to Alzheimer's disease pathogenesis. Neurotoxicology 2016, 53, 350-358. [CrossRef]

26. Siracusa, R.; Fusco, R.; Peritore, A.F.; Cordaro, M.; D’Amico, R.; Genovese, T.; Gugliandolo, E.; Crupi, R.; Smeriglio, A.; Mandalari, G.; et al. The Antioxidant and Anti-Inflammatory Properties of Anacardium occidentale L. Cashew Nuts in a Mouse Model of Colitis. Nutrients 2020, 12, 834. [CrossRef]

27. Impellizzeri, D.; Siracusa, R.; Cordaro, M.; Peritore, A.F.; Gugliandolo, E.; Mancuso, G.; Midiri, A.; Di Paola, R.; Cuzzocrea, S. Therapeutic potential of dinitrobenzene sulfonic acid (DNBS)-induced colitis in mice by targeting IL-1beta and IL-18. Biochem. Pharmacol. 2018, 155, 150-161. [CrossRef]

28. Cordaro, M.; Impellizzeri, D.; Gugliandolo, E.; Siracusa, R.; Crupi, R.; Esposito, E.; Cuzzocrea, S. Adelmidrol, a Palmitoylethanolamide Analogue, as a New Pharmacological Treatment for the Management of Inflammatory Bowel Disease. Mol. Pharmacol. 2016, 90, 549-561. [CrossRef]

29. Casili, G.; Cordaro, M.; Impellizzeri, D.; Bruschetta, G.; Paterniti, I.; Cuzzocrea, S.; Esposito, E. Dimethyl Fumarate Reduces Inflammatory Responses in Experimental Colitis. J. Crohns Colitis 2016, 10, 472-483. [CrossRef]

30. Bednar, M.; Smith, B.; Pinto, A.; Mullane, K.M. Neutrophil depletion suppresses 111In-labeled platelet accumulation in infarcted myocardium. J. Cardiovasc. Pharmacol. 1985, 7, 906-912. [CrossRef]

31. Fusco, R.; Siracusa, R.; D’Amico, R.; Peritore, A.F.; Cordaro, M.; Gugliandolo, E.; Crupi, R.; Impellizzeri, D.; Cuzzocrea, S.; di Paola, R. Melatonin Plus Folic Acid Treatment Ameliorates Reserpine-Induced Fibromyalgia: An Evaluation of Pain, Oxidative Stress, and Inflammation. Antioxidants 2019, 8, 628. [CrossRef] [PubMed]

32. D'Amico, R.; Fusco, R.; Gugliandolo, E.; Cordaro, M.; Siracusa, R.; Impellizzeri, D.; Peritore, A.F.; Crupi, R.; Cuzzocrea, S.; di Paola, R. Effects of a new compound containing Palmitoylethanolamide and Baicalein in myocardial ischaemia/reperfusion injury in vivo. Phytomedicine 2019, 54, 27-42. [CrossRef] [PubMed]

33. Fusco, R.; Cordaro, M.; Siracusa, R.; D'Amico, R.; Genovese, T.; Gugliandolo, E.; Peritore, A.F.; Crupi, R.; Impellizzeri, D.; Cuzzocrea, S.; et al. Biochemical Evaluation of the Antioxidant Effects of Hydroxytyrosol on Pancreatitis-Associated Gut Injury. Antioxidants 2020, 9, 781. [CrossRef] [PubMed]

34. Cordaro, M.; Siracusa, R.; Impellizzeri, D.; D'Amico, R.; Peritore, A.F.; Crupi, R.; Gugliandolo, E.; Fusco, R.; Di Paola, R.; Schievano, C.; et al. Safety and efficacy of a new micronized formulation of the ALIAmide palmitoylglucosamine in preclinical models of inflammation and osteoarthritis pain. Arthritis Res. Ther. 2019, 21, 254. [CrossRef]

35. Strober, W.; Fuss, I.; Mannon, P. The fundamental basis of inflammatory bowel disease. J. Clin. Investig. 2007, 117, 514-521. [CrossRef]

36. Bouma, G.; Strober, W. The immunological and genetic basis of inflammatory bowel disease. Nat. Rev. Immunol. 2003, 3, 521-533. [CrossRef]

37. Neurath, M.F.; Finotto, S.; Fuss, I.; Boirivant, M.; Galle, P.R.; Strober, W. Regulation of T-cell apoptosis in inflammatory bowel disease: To die or not to die, that is the mucosal question. Trends Immunol. 2001, 22, 21-26. [CrossRef]

38. Zhao, H.; Wu, L.; Yan, G.; Chen, Y.; Zhou, M.; Wu, Y.; Li, Y. Inflammation and tumor progression: Signaling pathways and targeted intervention. Signal Transduct. Target. Ther. 2021, 6, 263. [CrossRef]

39. Szumilas, D.; Krysiak, R.; Okopien, B. The role of TLR4 receptor in development of inflammation and carcinogenesis in ulcerative colitis and pharmacotherapy of this disorder. Wiad. Lek. 2013, 66, 3-9.

40. Jedrzejewski, T.; Sobocinska, J.; Pawlikowska, M.; Dzialuk, A.; Wrotek, S. Extract from the Coriolus versicolor Fungus as an Anti-Inflammatory Agent with Cytotoxic Properties against Endothelial Cells and Breast Cancer Cells. Int. J. Mol. Sci. 2020, 21, 9063. [CrossRef]

41. Saleh, M.H.; Rashedi, I.; Keating, A. Immunomodulatory Properties of Coriolus versicolor: The Role of Polysaccharopeptide. Front. Immunol. 2017, 8, 1087. [CrossRef] [PubMed]

42. Yang, S.F.; Zhuang, T.F.; Si, Y.M.; Qi, K.Y.; Zhao, J. Coriolus versicolor mushroom polysaccharides exert immunoregulatory effects on mouse B cells via membrane Ig and TLR-4 to activate the MAPK and NF-kappaB signaling pathways. Mol. Immunol. 2015, 64, 144-151. [CrossRef] [PubMed]

43. Wang, D.; Calabrese, E.J.; Lian, B.; Lin, Z.; Calabrese, V. Hormesis as a mechanistic approach to understanding herbal treatments in traditional Chinese medicine. Pharmacol. Ther. 2018, 184, 42-50. [CrossRef] [PubMed]

44. Kappeler, A.; Mueller, C. The role of activated cytotoxic T cells in inflammatory bowel disease. Histol. Histopathol. 2000, 15, 167-172. [CrossRef]

45. Funderburg, N.T.; Stubblefield Park, S.R.; Sung, H.C.; Hardy, G.; Clagett, B.; Ignatz-Hoover, J.; Harding, C.V.; Fu, P.; Katz, J.A.; Lederman, M.M.; et al. Circulating CD4(+) and CD8(+) T cells are activated in inflammatory bowel disease and are associated with plasma markers of inflammation. Immunology 2013, 140, 87-97. [CrossRef]

46. Rabe, H.; Malmquist, M.; Barkman, C.; Ostman, S.; Gjertsson, I.; Saalman, R.; Wold, A.E. Distinct patterns of naive, activated and memory $\mathrm{T}$ and B cells in blood of patients with ulcerative colitis or Crohn's disease. Clin. Exp. Immunol. 2019, 197, 111-129. [CrossRef] 
47. Bullard, D.C.; Kunkel, E.J.; Kubo, H.; Hicks, M.J.; Lorenzo, I.; Doyle, N.A.; Doerschuk, C.M.; Ley, K.; Beaudet, A.L. Infectious susceptibility and severe deficiency of leukocyte rolling and recruitment in E-selectin and P-selectin double mutant mice. J. Exp. Med. 1996, 183, 2329-2336. [CrossRef]

48. Mittal, M.; Siddiqui, M.R.; Tran, K.; Reddy, S.P.; Malik, A.B. Reactive oxygen species in inflammation and tissue injury. Antioxid. Redox Signal. 2014, 20, 1126-1167. [CrossRef]

49. Fang, Y.Z.; Yang, S.; Wu, G. Free radicals, antioxidants, and nutrition. Nutrition 2002, 18, 872-879. [CrossRef]

50. Sharifi-Rad, M.; Anil Kumar, N.V.; Zucca, P.; Varoni, E.M.; Dini, L.; Panzarini, E.; Rajkovic, J.; Tsouh Fokou, P.V.; Azzini, E.; Peluso, I.; et al. Lifestyle, Oxidative Stress, and Antioxidants: Back and Forth in the Pathophysiology of Chronic Diseases. Front. Physiol. 2020, 11, 694. [CrossRef]

51. Wardyn, J.D.; Ponsford, A.H.; Sanderson, C.M. Dissecting molecular cross-talk between Nrf2 and NF-kappaB response pathways. Biochem. Soc. Trans. 2015, 43, 621-626. [CrossRef] [PubMed]

52. Fan, H.; Chen, W.; Zhu, J.; Zhang, J.; Peng, S. Toosendanin alleviates dextran sulfate sodium-induced colitis by inhibiting M1 macrophage polarization and regulating NLRP3 inflammasome and Nrf2/HO-1 signaling. Int. Immunopharmacol. 2019, 76, 105909. [CrossRef] [PubMed]

53. Calabrese, V.; Cornelius, C.; Maiolino, L.; Luca, M.; Chiaramonte, R.; Toscano, M.A.; Serra, A. Oxidative stress, redox homeostasis and cellular stress response in Meniere's disease: Role of vitagenes. Neurochem. Res. 2010, 35, 2208-2217. [CrossRef] [PubMed] 